\title{
UN ACERCAMIENTO A LA \\ LINGÜÍSTICA SINCRÓNICA EN LA ÉPOCA ACTUAL EN TOLUCA, ESTADO DE MÉXICO: EL ESPAÑOL Y EL NÁHUATL
}

\author{
Alejandra Espinosa Segura \\ Universidad Autónoma del Estado de México \\ http://dx.doi.org/10.18778/8220-201-4.06
}

\section{Resumen}

Es una investigación enfocada al siglo XXI en la ciudad de Toluca sobre la forma en que se habla, muchos de los términos provienen de las lenguas madre de esta localidad, que en este caso, son lenguas indígenas, pero solo retomamos el náhuatl, pues ahí se encuentran los mejores ejemplos que aún conservamos dentro del español. También retomamos algunas definiciones de lingüística, sincronía y teorías como apoyo y poder así dar una mejor explicación sobre el habla y lenguaje que se practica tanto en la ciudad como en el país y cómo es que el español de alguna forma ha modificado los vocablos en su lengua original.

Palabras clave: Lingüística sincrónica, náhuatl, habla cotidiana.

1.

\section{Introducción}

En este trabajo se expondrán, como lo dice el título, los usos que se pueden encontrar en el habla de las lenguas hispánicas como el español y el náhuatl, pues de esta última, se han extraído muchos términos, haciéndoles algunas modificaciones para adecuarlo a la pronunciación de nuestro idioma. Consta de dos partes: en la 
primera, se mostrarán las influencias del náhuatl sobre el idioma español y en la segunda, se hará mención de los estudios lingüísticos aplicados a las dos lenguas que hemos decidido abordar. El objetivo es dar a conocer que nuestro lenguaje proviene de una de las lenguas indígenas más famosas en el centro de la ciudad y que a pesar de haber sido conquistados, la lengua aún conserva vocablos de nuestro lengua original. Para eso comenzaremos a hablar sobre la cultura náhuatl y a continuación daremos ejemplos de esos términos que todavía usamos.

\section{2.}

\section{Glífica náhuatl}

Los glifos del náhuatl parecen ser algo complicados y confusos, las versiones populares, las transcripciones disparatadas, supresión de párrafos claves y citas importantes fueron algunos de los elementos que generaban confusión a los cronistas para compilar las crónicas históricas y así dar a conocer la verdadera glífica. Con la independencia, se dio la decadencia de estudios sobre la lengua mexicana. Políticamente, indios y españoles eran iguales, inclusive habían hecho más por la lengua los españoles que los propios mexicanos.

La mayoría de los libros en náhuatl son anteriores a la independencia, por lo tanto, sus documentos son valiosos, no solo para la historia, sino también para la cultura universal y "para que esta amplia y abundante, rica y variada literatura sea leída y sea estimada, es necesario que se aprenda la lengua en que se halla escrita" (Garibay, 2007: 330).

\section{3.}

\section{Vocablos del náhuatl que han influido en el español}

Existen muchos términos que se usan comúnmente en el español, que en su mayoría provienen de una lengua indígena: el náhuatl. Es por eso que que debemos conocer su cultura y, sobre todo, 
dominar el idioma, pues son y seguirán siendo nuestras raíces, prueba de ello está en que una parte de nuestra lengua se basa en sus vocablos. Cabe destacar que la lengua hablada está en constante cambio, el español no es la excepción, somos los hablantes quienes nos encargamos a través del uso cotidiano de incorporar nuevos términos, olvidarnos de otros y hasta cambiar pronunciaciones o conjugaciones, así que desde un estudio sincrónico, nos aproximaremos al uso de algunos vocablos coloquialmente usados en Toluca, México.

Existen palabras del náhuatl que, afortunadamente, han permanecido en el español que se habla en México. El uso del diminutivo, por ejemplo, en el náhuatl prehispánico era común para designar respeto o cariño, contrariamentemente a lo que se ve en el español, que refiere usualmente a la pequeñez, respecto a esto podría decir que se ha convertido en un vicio del lenguaje, porque palabras como minutito, tantito, ahorita, son tan comunes que no notamos que se están usando en diminutivo, y por lo tanto, que son alusivos a un tamaño menor.

Volviendo a los nahuatlismos, a continuación enlistamos algunas de las palabras del náhuatl que continuamos utilizando. Dicha información fue obtenida de artículos electrónicos de revistas actuales como "Sin embargo" y "Algarabía", que son consultados por público, en su mayoría, joven, y así, acercan a la población a su propia lengua, la misma que usan de manera cotidiana.

Xocolatl, hispanizado y modificado da como resultado el término chocolate, el cual, es un producto del cacao de origen totalmente mexicano. Su sabor logró cautivar a los europeos, quienes se apropiaron de él y modificaron su uso agregando leche y transformándolo en bebida. No ha y que dejar de mencionar que es un producto de origen prehispánico que se consume en todo el mundo.

El tiyanquiztli, usado para los lugares de compra-venta prehispánicos, significa mercado; traducido al español, es un tianguis. En ellos se realizaba su comercio, actualmente se usa dicha palabra para referirse a lugares mercantiles de carácter informal o que no están propiamente establecidos. 
Milpa deriva del náhuatl milli, que significa tierra sembrada y pan, cuyo significado es encima. Al enlazarlas, su resultado refiere a lo que se siembra sobre la tierra, y generalmente designa al área de cultivo en pequeña escala o la parcela. El uso de esta palabra es muy común en el contexto del campo.

Entre los alimentos hay tres ejemplos: el primero, atolli, adaptado al español como atole, se refiere a una bebida hecha a base de harina de maíz disuelta en agua o leche; el segundo, chillaquílitl, que es un platillo a base de tortillas de maíz despedazadas, pueden ser fritas y remojadas en salsa de chile, que actualmente varía entre verde o rojo, antes, solo era verde, a este se le llama en el español como chilaquiles; y el tercero, tamalli, adoptado en el español como tamal, es una porción de masa envuelta en hojas de maíz o de plátano y cocida al vapor.

Respecto a los animales se tiene al centzontli, mejor conocido como cenzontle, que es un ave que puede imitar los cantos de otros pájaros; el huexólotl, o mejor dicho, guajolote, es un ave americana doméstica comestible, idéntica al pavo; y finalmente el quetzalli, que es tal vez, el más representativo de la cultura náhuatl, se refiere a un ave de intenso color verde, cuyas largas plumas eran sumamente apreciadas por la realeza mexica, conocida en el español como quetzal. Por último, haremos referencia a las plantas que de dicha cultura provienen. Empezaremos con la más conocida y usada, pero que, desgraciadamente, no muchos conocen de su origen: el cempoaxóchitl, nombrado por todos como cempasúchil, es una flor amarilla parecida al clavel, que forma parte de la ofrenda tradicional del Día de Muertos. Su popularidad llega junto con su oferta y demanda por los meses de octubre y noviembre en todo México.

Como otro ejemplo popular se encuentra el ahuácatl, el conocido y sabroso aguacate, árbol de sabroso fruto cuyas hojas se usan como condimento, de un sabor exquisito y suave a avellana. Su consistencia tierna y cremosa permiten su combinación con cualquier alimento; específicamente en México este se come con chile y sal, en cambio, en otros países de Latinoamérica se come con azúcar y en forma de licuado, pues las tradiciones y costumbres son diferentes en cada lugar. 
En cuanto a los cantos, había varios, el más importante era el teocuicatl, un canto divino donde se hacía alusión a cuestiones esotéricas y metáforas. Estos trataban sobre temas religiosos, que se cantaban y representaban. "El canto de Quetzalcóatl" es el más famoso dentro del género.

\section{4. \\ Sincronía}

Al hablar de lingüística sincrónica, el objetivo de este texto es tomar en cuenta solo una perspectiva: el presente de los hablantes, pues "su método consiste en recoger su testimonio; para saber en qué medida una cosa es una realidad, habrá que buscar...en qué medida existe para la conciencia de los sujetos" (Saussure, 1998 [1916]: 130). En este caso, los testimonios están basados en la población toluqueña actual, pues de ellos hemos podido extraer los vocablos que intentamos dar a conocer. La sincronía se utiliza para expresar un orden existente, aunque también puede ser precario, igualmente, y permite ver un estado de las cosas; resalta el sentido de disposición, es más bien, un principio de regularidad. "La lengua es un vestido cubierto de remiendos hechos con su propia tela" (Saussure, 1998 [1916]: 230), y es así como se considera a la lengua, como un rasgo característico de cada lugar. Se dice que dos idiomas pueden vivir juntos en un mismo lugar y coexistir sin confundirse, es el caso de México, donde el español se ha superpuesto a la lengua de la población indígena y de esta forma se implantó en el país para nunca irse.

Saussure afirma en el Curso de lingüística general que no hay que pensar que el idioma trasplantado se modificará solo y que el idioma originario permanecerá inmóvil. En este caso el idioma original funciona en forma de dialectos. En cuanto a esto, "es difícil decir en qué consiste la diferencia entre una lengua y un dialecto. Con frecuencia un dialecto lleva el nombre de lengua porque ha producido una literatura" (Saussure, 1998 [1916]: 269). Al respecto debemos decir que la literatura náhuatl no tomó gran relevancia, pues la mayoría de sus escritos han desaparecido, 
o bien, fueron traducidos por españoles, como es el caso del fraile Bernardino de Sahagún con sus aportaciones como El códice florentino o La historia general de las cosas de la Nueva España.

\section{5.}

\section{Lenguas indígenas}

Por otro lado, el náhuatl toma un papel importante en la lengua actual de los mexicanos, pues regresando a la época de la conquista, "el náhuatl se empezó a imponer como lengua oficial en todo el imperio y fue adquiriendo prestigio como lengua de poder y de cultura" (Blecua, 1990: 37), incluso se dice que los aztecas manifestaban desprecio por aquellos que no hablasen náhuatl.

Tanto la lingüística comparada como la reconstrucción de lenguas han permitido relacionar genéticamente varios idiomas actuales, como es la fusión del español con el náhuatl. Actualmente, se dice que los idiomas nativos no tienen una historia documental apreciable y que sólo se puede hacer lingüística histórica de lenguas indoeuropeas.

Al comparar la forma de hablar de los hablantes de lengua náhuatl y de español mexicano, podemos deducir que los hablantes de náhuatl pueden entendernos bien cuando usamos el español, en cambio para nosotros, hablantes nativos de español es conflictivo entenderles. En el área de Toluca se comprueba por completo el habla de otra lengua indígena: el otomí. Aportaremos algunos ejemplos que se siguen usando, de manera consciente o inconsciente, en la población.

Algunas de las peculiaridades gramaticales en esta lengua son:

- Omisión de artículo definido: día que se case

- Omisión de artículo indefinido: ya creció poquito más mejorcito

- Uso redundante del pronombre lo: como que no lo quieres a tu papá (como que no quieres a tu papá)

- Omisión de preposiciones: empecé ir (empecé a ir), ahora lo que yo me preocupo (ahora por lo que yo me preocupo).

En cuanto a características léxicas: 
- Uso frecuente del ya: ya crecieron mis hijos, para plantarlo ya, empezamos ya a caminar.

- Intercambio de conocer por saber: ni lo conocíamos qué era la hortaliza (ni sabíamos qué era la hortaliza)

- Intercambio de hacer por tener: la costumbre que hacemos (la costumbre que tenemos).

En fin, son solo unos ejemplos porque la lista puede ser más grande; es una forma de mostrar que Toluca, en su completa población, puede llegar a ser bilingüe, aunque falta perfección y práctica para dominar dos lenguas. Es imprescindible por lo menos, conocer las dos, es solo cuestión de contexto para poder entenderse entre un hablante de español y otro de lengua indígena. Actualmente, se empieza por incorporar nahuatlismos en el español. Esperemos que, posteriormente, seamos muchos los que dominemos tanto el español como nuestras lenguas madres, las indígenas.

Como resultado final a este estudio, se observa que el vocabulario mexicano, más aún el mexiquense está plagado de nahuatlismos y otras características de lenguas indígenas, incluido el otomí, como previamente hemos mencionado; los grupos étnicos, fieles representantes de estas lenguas, han pasado también por múltiples transformaciones como el español. Hoy en día, representan alrededor del 10\% de la población de México. Su importancia es relativa, en ocasiones su presencia es nula, y en otras, tiene gran fuerza. Por otro lado, hay que destacar que estos grupos son los principales productores de alimentos básicos y materias primas como maíz, azúcar, café, chile, cacao, tabaco, etc.

Desgraciadamente, también la opresión llega a la lingüística; a las lenguas indígenas, por considerarlas inferiores, se les llama "dialectos", que en hablas cotidianas, implica carencias expresivas, estructurales y literarias, lo cual puede ser debido a que, como ya se había dicho, su literatura está perdida. Su expresividad se presta a múltiples interpretaciones ya que el léxico que manejan es diferente al español que en México se habla. Ello se manifiesta también en la sintáxis, por ejemplo, en una oración, lo que ellos refieren al objeto, los hispanohablantes lo podemos asumir como sujeto o complemento de objeto, y así pueden surgir muchos ejemplos de contrariedad. 
Sin embargo, tanto náhuatl como otomí, maya, zapoteca y muchas otras formas de comunicación en esta rama son, como referimos durante todo el escrito, lenguas, por el simple hecho de tener un sistema escrito y de comunicación. Muchos hablantes nativos del español están interesados en aprender y dominar estas lenguas que por cultura les pertenecen; aunque por otra parte, son incontables las personas indígenas que niegan hablar su lengua materna o peor aún, dejan de hablarla al grado de que sus generaciones futuras lleguen a olvidarlas, todo para ser aceptados dentro de la sociedad, sociedad que es una sola, pues todos los mexicanos tienen esas raíces y hasta las involucran en su habla coloquial.

"Las lenguas indígenas han sido declaradas lenguas nacionales, pero no oficiales" (Blecua, 1990: 599), eso impide su completo estudio y solo queda aceptar, y de alguna manera, incluir más de sus vocablos en nuestro español. En cuanto a la sincronía de la lengua, podemos concluir que por el momento está en auge el bilingüismo mexicano. Lo denominamos así, porque las dos lenguas que se involucran pertenecen al país, esto es, la combinación del español con alguna lengua indígena. Dicha labor sirve para comunicarse y también puede ser para elevar la cultura indígena, pues al entendernos mejor, podemos hacer una comunidad, o mejor dicho, un país incluyente, donde el habla de todos sea entendida por todos.

\section{Referencias bibliográficas}

Blecua, J. y otros (1990), Estudios de lingüística de España y México, México: UNAM.

Garibay, Á. (2007), Llave del náhuatl, México: Porrúa.

Motte, K. (2015), “Microhistorias: Nahuatlismos en español”, [en línea] <http://www.sinembargo.mx/13-06-2015/1376853>, [fecha de consulta: 24.11.2017].

Naves, A. (2015), "Glosario de nahuatlismos I”, [en línea] < http:// algarabia.com/lengua/glosario-de-nahuatlismos-i/>, [fecha de consulta: 22.11.2017].

Saussure, F. (1998 [1916]), Curso de lingüística general, México: Fontamara. 